\title{
Endoscopic submucosal dissection for a precancerous lesion emerging at the anastomotic site after radical resection of rectal carcinoma
}

The emergence of a precancerous lesion at the anastomotic site after radical resection of a rectal cancer is very rare [1, 2]. A salvage operation is one of the main treatments in this situation, but is a significant burden for the patient, both physically and economically $[3,4]$.

A 47-year-old man with a laterally spreading tumor (LST) at the site of the anastomosis with the rectum (about $3-5 \mathrm{~cm}$ from the anal margin) was admitted to our department ( $\triangleright$ Fig. 1 a, b). He had undergone total mesorectal excision combined with neoadjuvant radiotherapy for rectal cancer (moderately differentiated adenocarcinoma, T4NOMO) 18 years previously.

The whole procedure was similar to a routine endoscopic submucosal dissection (ESD), and included marking, submucosal injection, pre-cutting, submucosal dissection, and wound treatment [5]. However, the most important step was that, when peeling away the anastomotic site, the DualKnife was hung on the anastomotic nail, thereby integrating the nail and the knife by means of the electric conduction effect ( V Video 1). It was then possible to peel off the tissue around the anastomotic nail and remove it.

Postoperative pathological results showed low grade intraepithelial neoplasia (LGIN) with negative horizontal and vertical margins, which met the criteria for curative resection. No complications, such as bleeding or perforation, occurred ( $\triangleright$ Fig. 1 c) and the wound was well healed 3 months after the operation ( Fig. 1d).

The difficulties of the operation were as follows: (i) the severity of submucosal adhesions at the anastomotic site ( $\mathbf{F i g . 2}$ ), which led to unclear demarcation of the intestinal tract at all levels; (ii) the anastomotic nail at the anastomotic site needed to be removed during the dissection process; (iii) in order to maintain the integ-
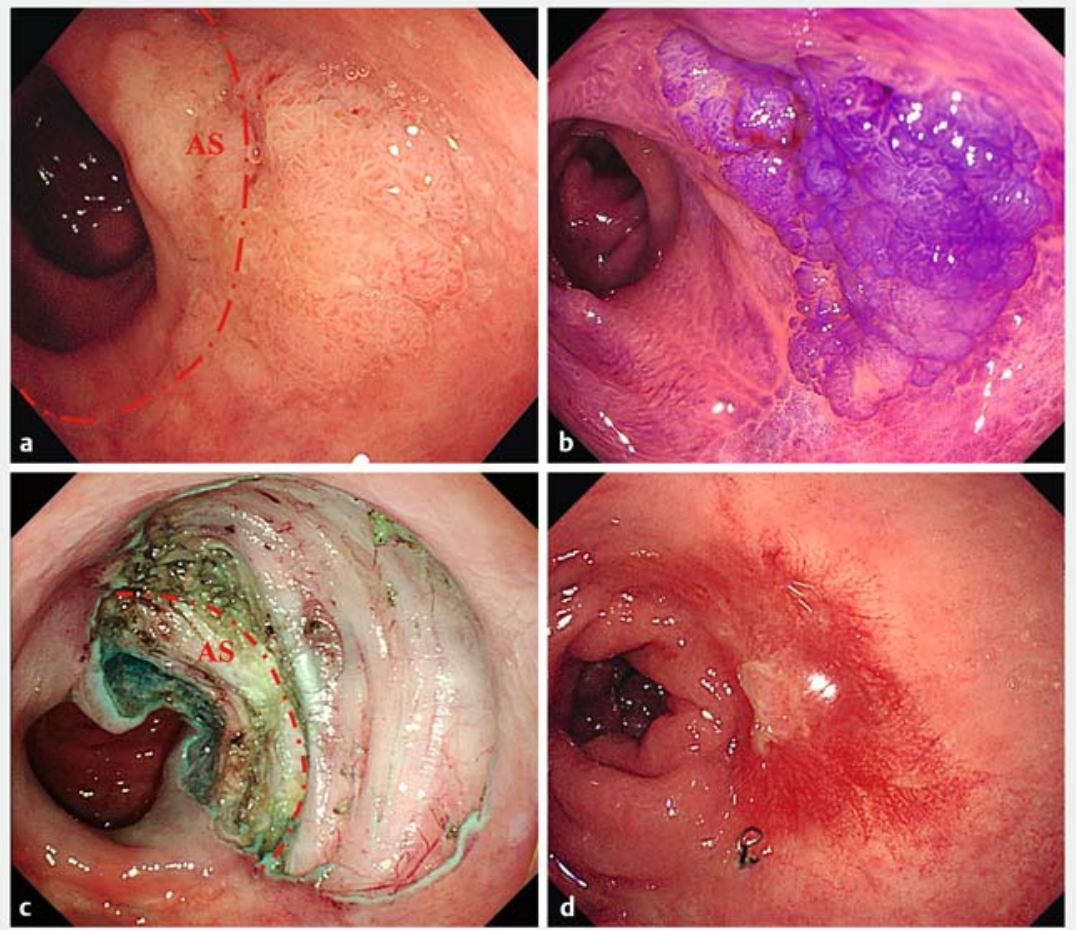

- Fig. 1 Colonoscopic images showing: a a laterally spreading tumor growing at the site of the anastomosis (AS) with the rectum (about $3-5 \mathrm{~cm}$ from the anal margin); $\mathbf{b}$ the lesion, with its boundary more clearly defined by crystal violet staining; $\mathbf{c}$ the wound after endoscopic submucosal dissection (ESD), with no evidence of bleeding or perforation; $\mathbf{d}$ the appearance during follow-up, with no evidence of recurrence.

rity of the tissue, we needed to carefully peel slightly deeper into the superficial intrinsic muscularis.

The significance of this method is that it can reduce the risk of reoperation for patients with precancerous lesions or early cancer emerging at an anastomotic site after colorectal cancer surgery. Particularly for lesions that are close to the anus, it can increase the rate of anal preservation, alleviate the trauma experienced by patients, and improve their quality of life.

Endoscopy_UCTN_Code_TTT_1AS_2AG
Funding

National Key R\&D Program of China 2016YFC0901402

Beijing Science and Technology Planning Project (CN)

D17110002617002

CAMS Innovation Fund for Medical Sciences (CIFMS)

2016-12M-1-001

Sanming Project of Medicine in Shenzhen No.SZSM201911008

\section{Competing interests}

The authors declare that they have no conflict of interest. 


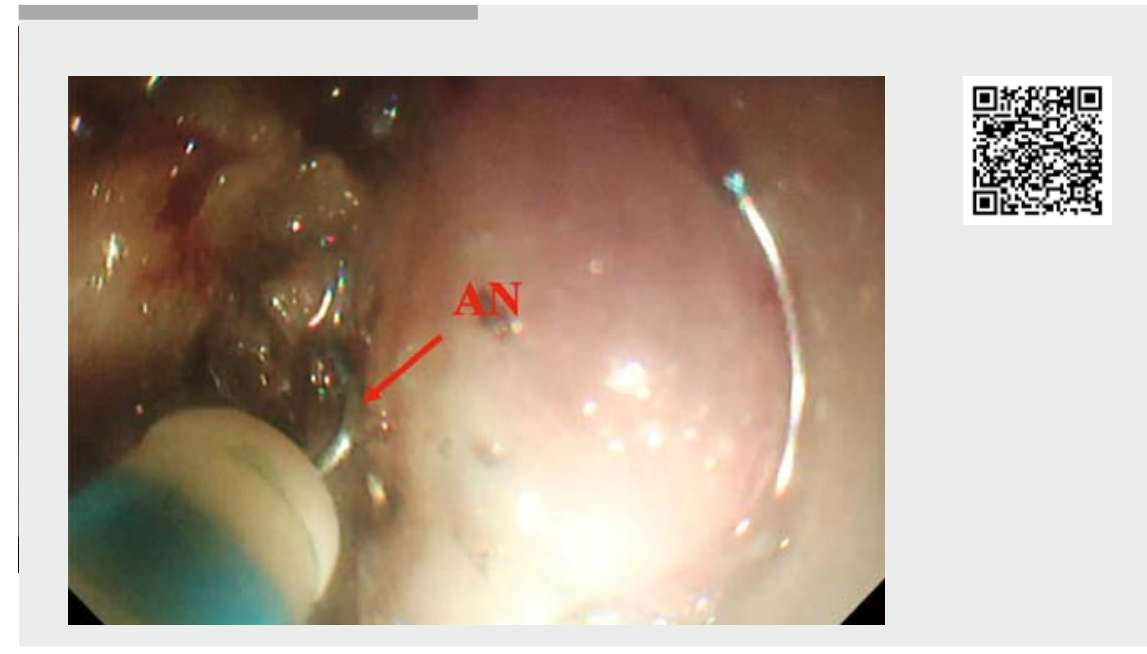

Video 1 The DualKnife was hung on the anastomotic nail (AN) when peeling off the anastomotic sites (AS), which integrated the nail and the knife by means of the electric conduction effect.

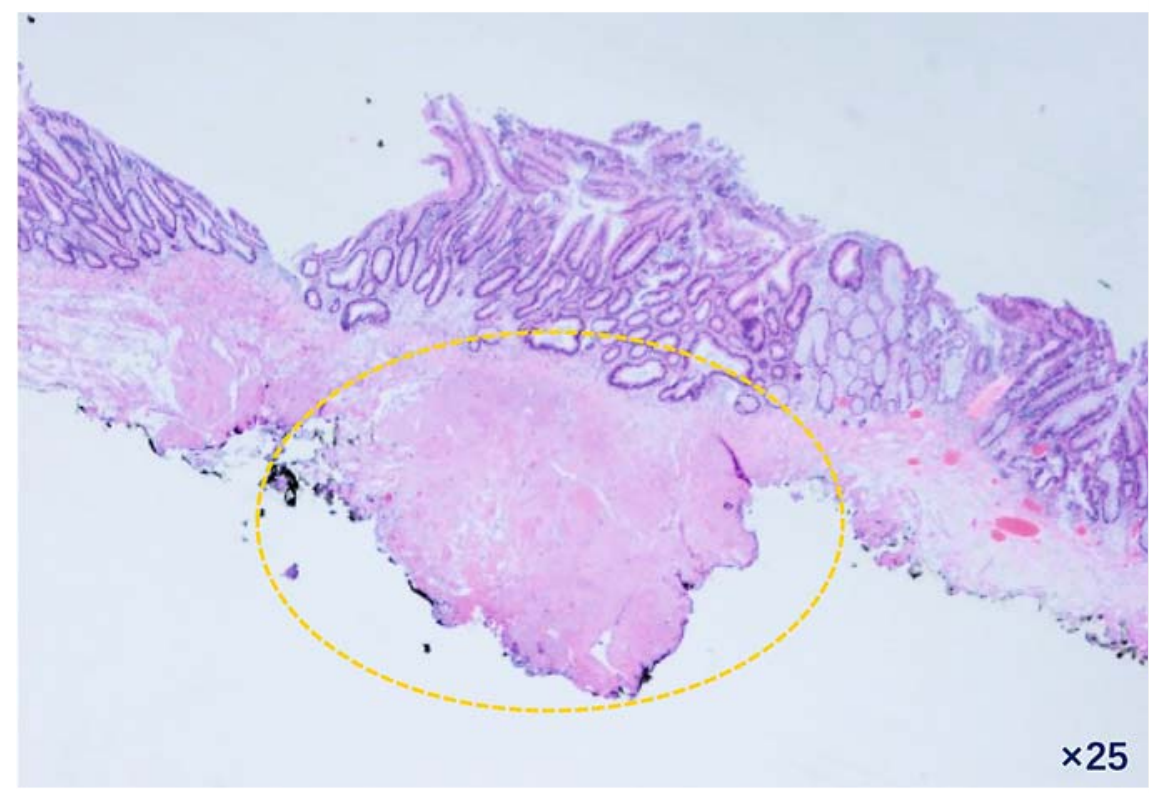

- Fig. 2 Pathological appearance of the resected lesion showing fibrous tissue hyperplasia and fibrous scar formation.

The authors

Zhihao Chen ${ }^{1}$, Lizhou Dou', Yueming Zhang', Shun $\mathrm{He}^{1}$, Yong Liu' ${ }^{1}$, Huizi Lei², Guiqi Wang ${ }^{1}$

1 Department of Endoscopy, National Cancer Center/National Clinical Research Center for Cancer/Cancer Hospital, Chinese Academy
Corresponding author

\section{Guiqi Wang, MD}

Department of Endoscopy, National Cancer Center/Cancer Hospital, Chinese Academy of Medical Sciences (CAMS), 17 Panjiayuannanli, Beijing, 100021, P. R. China Fax: +86-10-87711782 wangguiq@126.com

\section{References}

[1] Jung WB, Yu CS, Lim SB et al. Anastomotic recurrence after curative resection for colorectal cancer. World J Surg 2016; 41: 285294

[2] Jones PF. Anastomotic recurrence of colorectal cancer. Gut 1987; 28: 1691-1692

[3] Lopez-Kostner F, Fazio VW, Vignali A et al. Locally recurrent rectal cancer: predictors and success of salvage surgery. Dis Colon Rectum 2001; 44: 173-178

[4] Sagar PM, Pemberton JH. Surgical management of locally recurrent rectal cancer. $\mathrm{Br}$ J Surg 1996; 83: 293-304

[5] Fuccio L, Ponchon T. Colorectal endoscopic submucosal dissection (ESD). Best Pract Res Clin Gastroenterol 2017; 31: 473-480

\section{Bibliography}

DOI https://doi.org/10.1055/a-1085-9291

Published online: 29.1.2020

Endoscopy 2020; 52: E269-E270

(c) Georg Thieme Verlag KG

Stuttgart · New York

ISSN 0013-726X

\section{ENDOSCOPY E-VIDEOS}

https://eref.thieme.de/e-videos

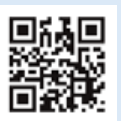

Endoscopy E-Videos is a free access online section, reporting on interesting cases and new techniques in gastroenterological endoscopy. All papers include a high quality video and all contributions are freely accessible online.

This section has its own submission website at https://mc.manuscriptcentral.com/e-videos 